\title{
Assessment of Misplaced Intrauterine Contraceptive Devices by Different Imaging Modalities: A Cross-sectional Study
}

\author{
Hesham E. Elsheikh ${ }^{\text {a, }}$ Manal A. ElRefaei ${ }^{\text {b }}$, Sara F. Abd Elfattah ${ }^{\text {a }}$
}

\begin{abstract}
a Department of Radiology,
Benha faculty of medicine, Benha University, Egypt.

b Department of Radiology, Al Ahrar teaching hospital, Cairo, Egypt.

Correspondence to: Sara F. Abd Elfattah, Department of Radiology, Benha faculty of medicine, Benha University, Egypt.
\end{abstract}

Email:

dr_saraelsemary@yahoo.com

Received: 12 December 2020

Accepted: 23 December 2020

\begin{abstract}
:
Background: Radiology plays a vital role in the diagnosis of intrauterine contraceptive device (IUCD) migration. Ultrasound (US) is used for initial evaluation. It is inexpensive and widely available. The X-ray is required for the diagnosis of (IUCD) expulsion as all (IUCDs) are radiopaque and rarely computed tomography (CT) is used. Aim of the study: Evaluation of the role of different radiological modalities in the assessment of malpositioned (IUCDs). Subjects and methods: A Cross-sectional study in the radiology department at Al Ahrar teaching hospital.
\end{abstract} Fifty patients were included with suspected misplaced (IUCD) over one year. Results: (US) was able to detect (IUCD) position in $88 \%$, while in $12 \%$ (IUCD) could not be localized. X-ray was performed for $42 \%$ and could confirm (US) result and exclude (IUCD) expulsion. (CT) was performed for $18 \%$ and could detect (IUCD) location when not seen in (US) and detect the associated complications. There was a significant agreement between the three diagnostic techniques and intraoperative findings. Conclusion: (US) is the first modality used in the diagnostic workup of the misplaced (IUCD), but it is not reliable if the omentum and bowel loops surround the device. The X-ray can help confirm (US) result and exclude expulsion. Rarely (CT) is used for (IUCD) localization. However, (CT) is the best for the evaluation of complications associated with intra-abdominal (IUCDs) and has a role in determining the proper method of removal.

Key words: Misplaced intrauterine contraceptive devices, Ultrasound, X-Ray, Computed tomography. 



\section{Introduction}

(IUCDs) are a frequently used method for contraception worldwide. They are highly effective, inexpensive, can be used for an extended period and rapidly reversible form of contraception. Two types of (IUCDs) are available: a copper-containing (IUCD) and a hormone-releasing (IUCD) [1].

The upper fundal part of the uterine cavity is the optimal position of the (IUCD). Malposition occurs if the (IUCD) is not positioned in the fundus uteri [2]. Migration of the (IUCD) from its normal position in the uterine fundus is a frequently encountered complication, varying from uterine expulsion to displacement into the endometrial canal to uterine perforation [3]. Radiology plays a vital role in the diagnosis of (IUCD) migration [1]. (US) is appropriate for initial evaluation; it is widely available and inexpensive and does not involve radiation. It easily helps determine whether an (IUCD) is correctly positioned and can often help identify (IUCD)-related complications such as contraceptive failure (pregnancy) and detection of fragmentation and calcification. (IUCD) displacement and myometrial perforation can be fully evaluated by performing (US) alone [4]. The $\mathrm{X}$-ray can help demonstrate an extra-uterine
(IUCD). It is required for the diagnosis of (IUCD) expulsion as all (IUCDs) are radiopaque [5]. Rarely (CT) is used for the assessment of (IUCD) position. It is the best for the evaluation of complications associated with intra-abdominal (IUCDs), such as visceral perforation, abscess formation, and bowel obstruction [6].

This work aimed to evaluate the role of different radiological modalities in the assessment of improperly positioned (IUCD).

\section{Subjects and methods}

This cross sectional study included 50 patients with suspected misplaced (IUCD). They were referred from the gynecology department to the radiology department at Al Ahrar teaching hospital during the period from June 2019 to March 2020. All clinical information was collected from the patient's files. After approval from the ethical committee, informed consent was obtained from all patients in the research. Inclusion criteria: patients clinically and radiologically suspected to have misplaced IUCD and this suspicion had been proved by different radiological modalities and patients approved to participate in the study. Exclusion criteria: patients that finally 
proved to have IUCD in place and patients refused to participate in the study.

All patients were subjected to grey-scale (US) examination of the abdomen and pelvis, first trans-abdominally then transvaginally using $3.5(\mathrm{MHz})$ and 5-7.5 $(\mathrm{MHz})$ transducers respectively. Cases with suspected penetration or negative (US) findings were subjected to X-ray, using traditional radiography machine with low doses of radiation. Cases with suspected complications were examined by (CT) (16 slice) according to the clinical supervision and sonographic findings. The (CT) examination was done while the patient lying in the supine position, cuts taken every $0.5-1 \mathrm{~cm}$.

IBM SPSS statistics (V. 23.0, IBM Corp., USA, 2015) was used for data analysis. Data were expressed as both percentage and number for categorized results. Diagnostic validity test was used, including an agreement between the studied radiological techniques and the intraoperative results. The probability of error equal to 0.05 was considered significant; while value at 0.01 and 0.001 are highly significant.

\section{Results:}

This study included 50 instances of misplaced (IUCD). We found that, as confirmed by operative results, 45 cases (90\%) had an unusual location within the pelvis (27cases $(54 \%)$ intrauterine, 18 cases (36\%) extra-uterine). Moreover, only 5 cases $(10 \%)$ had it in the intra-abdominal cavity.

The mean age of the included cases was 33.82 years (range 21-48years) (table 1). The parity of the studied group ranged from one to six (Fig. 1). The most frequent (IUCD) type was cupper T 66\%. The most frequent complaint among the studied group was abdominal and pelvic pain $34 \%$, followed by the inability to feel the threads $22 \%$ (Fig. 2). The most common methods of removal founded among the studied cases were hysteroscopy 40\%, followed by laparoscopy 36\% (Fig. 3).

According to (US), in $12 \%$ of the studied cases the (IUCD) was invisible, in $32 \%$ was embedded in the myometrium, in $14 \%$ in Douglas pouch. There was highly statistical significant strong agreement between (US) and intraoperative findings among the studied cases with sensitivity $88 \%$ (table 2). $58 \%$ of the studied cases had not done Xray. Among cases had X-ray most frequent places for (IUCD) was midline pelvis, (Lt) pelvis and (Rt) pelvis $(16 \%, 10 \%$ \& 6\% respectively). $82 \%$ of the studied cases had not done (CT). Among cases had (CT) $8 \%$ 
had (IUCD) intra-abdominal within omentum without perforation. There was highly statistical significant perfect agreement between (CT), X-ray and intraoperative findings among the studied cases (Table 3) (Table 4).

Table (1): Age of the studied cases.

\begin{tabular}{ll}
\hline Variable & $(\mathbf{n}=\mathbf{5 0})$ \\
\hline Age $:$ (year) & \\
Mean \pm SD & $33.82 \pm 7.45$ \\
Range & $21-48$ \\
\hline
\end{tabular}

SD: Standard deviation

Table (2): Agreement between (US) \& Intraoperative findings among the studied cases.

\begin{tabular}{|c|c|c|c|c|c|c|}
\hline \multirow[t]{2}{*}{ Variable } & \multicolumn{2}{|c|}{$\begin{array}{l}\text { US } \\
(n=50)\end{array}$} & \multicolumn{2}{|c|}{$\begin{array}{l}\text { Intraoperative } \\
(\mathbf{n}=50)\end{array}$} & \multirow[t]{2}{*}{ Kappa } & \multirow[t]{2}{*}{$\mathbf{P}$} \\
\hline & No & $\%$ & No & $\%$ & & \\
\hline \multicolumn{7}{|l|}{ Intraoperative: } \\
\hline Low IUD & 5 & 10 & 5 & 10 & & \\
\hline Displaced by fibroid & 4 & 8 & 4 & 8 & & \\
\hline Displaced by pregnancy & 2 & 4 & 2 & 4 & 0.92 & $<0.001$ \\
\hline Embedded to myometrium & 16 & 32 & 16 & 32 & & $* *$ \\
\hline Perforating myometrium & 2 & 4 & 2 & 4 & & \\
\hline Adnexa & 3 & 6 & 3 & 6 & & \\
\hline Douglas Pouch & 7 & 14 & 7 & 14 & & \\
\hline Perforating $U B$ & 1 & 2 & 1 & 2 & & \\
\hline Pelvic cavity & 4 & 8 & 5 & 10 & & \\
\hline Not in the pelvic cavity (intraabdominal) & 0 & 0 & 5 & 10 & & \\
\hline Not Visualized & 6 & 12 & 0 & 0 & & \\
\hline Sensitivity $=88 \% \quad P P V=100 \%$ & & & & & & \\
\hline
\end{tabular}

Kappa: Cohen's kappa test of agreement $\quad * *$ : Highly significant $\mathrm{P}<0.001$ ) 
Benha medical journal vol. 38, special issue (Radiology), 2021

Table (3): Agreement between X-ray \& Intraoperative findings among the studied cases.

\begin{tabular}{|c|c|c|c|c|c|c|c|c|c|}
\hline \multirow{3}{*}{ Variable } & \multicolumn{8}{|c|}{$X$-ray $\quad(n=21)$} & \multirow{3}{*}{$\mathbf{P}$} \\
\hline & Midline & $\mathbf{R t}$ & Lt p & $\mathbf{R t}$ & $\mathbf{R t}$ & $\mathbf{L t}$ & $\mathbf{L t}$ & Kappa & \\
\hline & & $\mathbf{p}$ & & UA & LA & UA & LA & & \\
\hline \multicolumn{10}{|l|}{ Intraoperative: } \\
\hline Embedded to myometrium & 5 & & & & & & & & \\
\hline Perforating myometrium & 2 & & & & & & & & \\
\hline Adnexa & & & 2 & & & & & 1 & $<0.001$ \\
\hline Douglas Pouch & & 2 & & & & & & & $* *$ \\
\hline Perforating $U B$ & 1 & & & & & & & & \\
\hline Pelvic cavity & & 1 & 3 & & & & & & \\
\hline Intar-abdominal & & & & 1 & 2 & 1 & 1 & & \\
\hline
\end{tabular}

Kappa: Cohen's kappa test of agreement $\quad * *$ : Highly significant $\mathrm{P}<0.001)$

Table (4): Agreement between (CT) \& Intraoperative findings among the studied cases.

\begin{tabular}{|c|c|c|c|c|c|c|}
\hline \multirow[b]{2}{*}{ Variable } & \multirow{2}{*}{$\begin{array}{l}\text { CT } \\
\text { No }\end{array}$} & \multirow{2}{*}{$\begin{array}{c}(n=9) \\
\%\end{array}$} & \multicolumn{2}{|c|}{ Intraoperative $(n=9)$} & \multirow[b]{2}{*}{ Kappa } & \multirow[b]{2}{*}{$\mathbf{P}$} \\
\hline & & & No & $\%$ & & \\
\hline \multicolumn{7}{|l|}{ Intraoperative: } \\
\hline Perforating myometrium & 2 & 22.2 & 2 & 22.2 & & \\
\hline Perforating $U B$ & 1 & 11.1 & 1 & 11.1 & & \\
\hline Intraabdominal, Perforating Bowel & 1 & 11.1 & 1 & 11.1 & 1 & $<0.001$ \\
\hline $\begin{array}{l}\text { Intraabdominal, within omentum without } \\
\text { perforation }\end{array}$ & 5 & 55.6 & 5 & 55.6 & & $* *$ \\
\hline
\end{tabular}

Kappa: Cohen's kappa test of agreement $\quad * *$ : Highly significant $\mathrm{P}<0.001)$ 


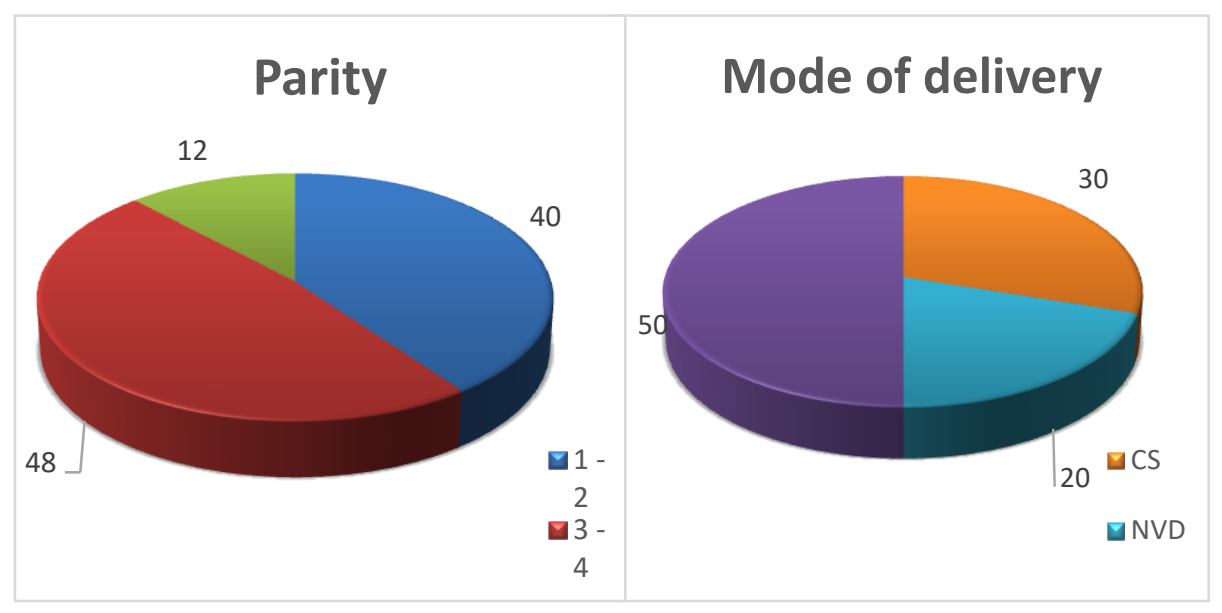

Figure (1): Parity \&mode of delivery among the studied cases.

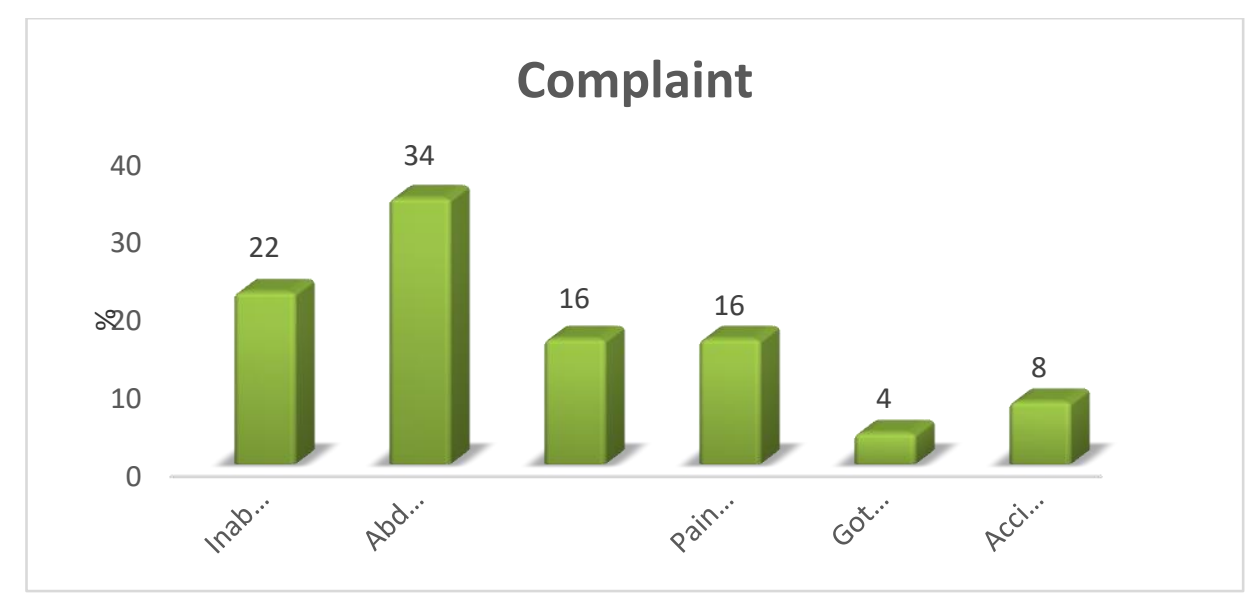

Figure (2): Complaint among the studied cases.

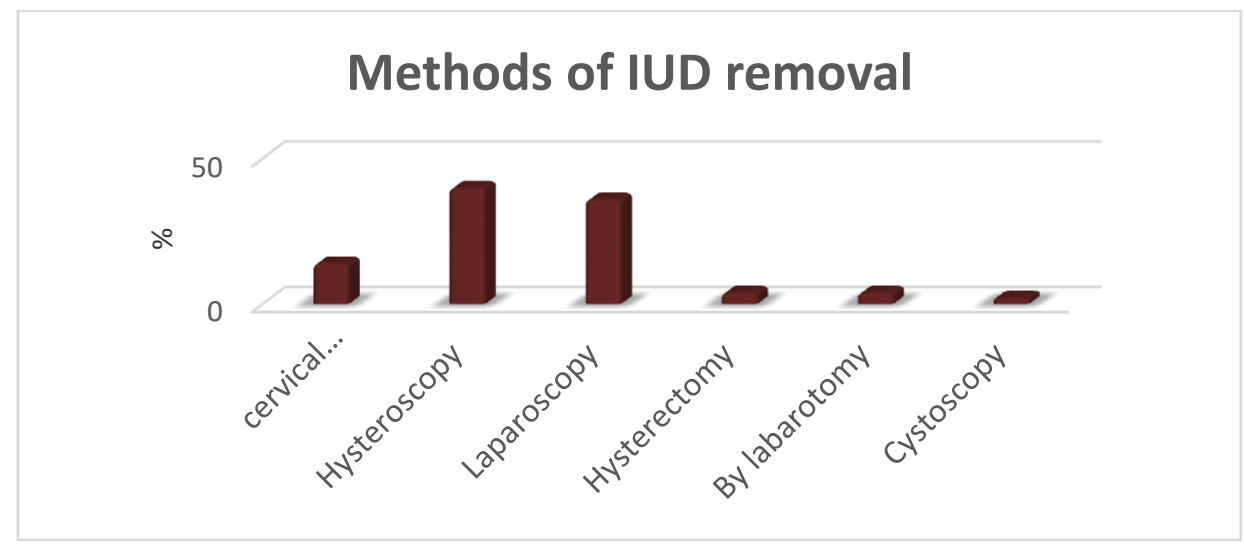

Figure (3): Methods of IUD removal among the studied cases. 



\section{Discussion}

(IUCDs) are commonly used for contraception worldwide. They are highly effective, inexpensive, can be used for an extended period and rapidly reversible form of contraception [1]. A copper or hormonereleasing (IUCD) optimal position is in the upper fundal portion of the uterine cavity. Malposition occurs if the (IUCD) is not positioned in the fundus uteri [2]. Migration of the (IUCD) from its normal position in the uterine fundus is a frequently encountered complication, ranging from uterine expulsion to displacement into the endometrial canal to uterine perforation [3]. Ultrasound (US) is appropriate for initial evaluation; it is widely available and inexpensive and does not involve radiation [4]. (IUCD) displacement and myometrial perforation can be fully evaluated by performing (US) alone. However, (US) is not reliable if the device is surrounded by the omentum and bowel loop [7, 8].

The X-ray can help demonstrate an extrauterine (IUCD) and is required for the diagnosis of (IUD) expulsion [5]. Rarely (CT) is used for the assessment of (IUCD) position. However, it is best for the evaluation of complications associated with intra-abdominal (IUCDs) [6].
This study included fifty patients with misplaced (IUCD); their age ranged from (21 to 48 ) years with a mean age of 33.82 years. In a study done in 2018 [9], the majority of the studied cases were aged 3039 years while in a study done in 2015 on 21 patients the mean age was of 29.4 years [10].

The most frequent (IUCD) type in the studied cases was cupper $\mathrm{T} 66 \%$ followed by hormonal $24 \%$ and only $10 \%$ had a multi-load type. Our findings are similar to other reported studies $[10,11]$. In this study, the time from insertion till diagnosis of missing ranged from 1 to 168 months with mean 31.18 months. According to another study done in 2016, the maximum number of patients had time interval of 18-24 months between insertion and diagnosis of missing [12].

The parity of the studied group ranged from one to six, with $48 \%$ had parity three to four times that are similar to another reported results $[12,10]$. Regarding delivery mode, the mean cesarean section (CS) times was 1.93 , and the mean normal vaginal delivery (NVD) times were 1.97. According to a study done in 2015 , the mean number of births by (NVD) was 2.5 , while the mean number of (CS) births was 0.4 [10]. The 
most frequent complaint among the studied group was abdominal and pelvic pain 34\%, followed by the inability to feel the threads $22 \%$. These results are in agreement with some reported studies $[11,13]$ while is controverted with another one [14].

(US) was performed for all patients as an initial evaluation to detect (IUCD) location. X-ray was performed for $42 \%$ of patients either to confirm (US) result or to exclude expulsion if (IUCD) could not be seen. (CT) was performed for $18 \%$ of patients to detect (IUCD) location when not seen in (US) and detect the associated complications. It also has a role in determining the proper method of removal. The results of US, X-ray and (CT) were correlated with that of operative procedures. Similarly, a study done in 2011 suggested using different radiological investigative modalities for localization of the missed (IUCD) [15].

According to (US), the (IUCD) was correctly positioned in $88 \%$ of cases to be found embedded in myometrium in $32 \%$, in Douglas pouch in $14 \%$, low displaced in $10 \%$, displaced by fibroid and in the pelvic cavity in $8 \%$ for both, in adnexa in $6 \%$ and displaced by pregnancy in $4 \%$. (IUCD) perforated myometrium in $4 \%$ and urinary bladder in $2 \%$. (IUCD) could not be localized in $12 \%$. There was a highly significant strong agreement between (US) and intraoperative findings among the studied cases. According to a reported study on 74 patients [16], misplaced (IUCD) could be properly diagnosed by (US), and this also was going with other previous studies [11, 9] in which $85 \%, 50 \%$ of cases respectively could be properly diagnosed by (US).

Twenty-one (42\%) cases had X-ray examination, the most frequent places for (IUCD) was midline pelvis, left pelvis and right pelvis $(16 \%, 10 \% \& 6 \%$ respectively). In $10 \%$ of cases, the (IUCD) was found in the abdomen. There was highly statistical significant perfect agreement between X-ray and intraoperative findings among the studied cases. According to a study done in 2018, $15 \%$ of cases could be diagnosed by X-ray [9]. Use of X-ray was the commonest mode of diagnosis $(50 \%)$ in a study reported in 2011 [15].

Nine (18\%) cases had (CT) examination, $8 \%$ had (IUCD) intra-abdominal within omentum without perforation, 4\% (IUCD) had it perforating myometrium and $2 \%$ had it extra-uterine in the pelvic cavity. Also, two cases had (IUCD) perforating urinary bladder and bowel one $2 \%$ for each. There was highly statistical significant perfect agreement between (CT) and intraoperative 
findings among the studied cases. Those findings are in agreement with studies which suggested using (CT) with other investigative modalities for localization of the missed (IUCD) $[15,17]$ but another study reported that $(\mathrm{CT})$ might be required very rarely in cases of transmigrated/misplaced (IUCD) [11].

The most common methods used for removal among the studied cases were hysteroscopy; laparoscopy and cervical dilatation and retrieval hook $(40 \%, 36 \% \&$ $14 \%$ respectively). According to a study done in 2019, 65\% of patients required hysteroscopic guided removal. In $20 \%$ of patients (IUCD) was removed using long artery forceps under anesthesia. 15\% of patients had laparoscopic removal and none required laparotomy [11].

Our study included 50 instances of Misplaced (IUCD). We found that, as confirmed by operative results, $90 \%$ had an unusual location within the pelvis, (54\% intrauterine and $36 \%$ extra-uterine). Only $10 \%$ had it in the intra-abdominal cavity. In $32 \%$ of cases (IUCD) was embedded in the myometrium, in $10 \%$ was low displaced, in $8 \%$ was displaced by fibroid, in $4 \%$ was displaced by pregnancy. Additionally in $14 \%$ (IUCD) was in Douglas pouch, in 10\% was in the pelvic cavity, in 6\% was in adnexa, in $4 \%$ (IUCD) perforated the myometrium, in $2 \%$ perforated the urinary bladder, in $8 \%$ (IUCD) was seen within omentum without perforation and in $2 \%$ perforated bowel wall. According to another study, $38.8 \%$ of the studied cases had (IUCD) within omentum without perforation, 22.2\% had it in Douglas pouch, $16.6 \%$ had it embedded to the myometrium, $11.1 \%$ had it perforating bowel and only one case $(5.5 \%)$ had it in adnexa and perforating UB for both of them [18]. A study done in 2015 reported that the most common extrauterine (IUCD) location was the Douglas pouch in $52.3 \%$ of the studied patients. The (IUCD) was found in adnexa and within omentum in $19 \%$ of cases for both of them and the rare location of the retro-peritoneum was seen in two cases [10].

\section{Conclusion}

(US) is the first modality used in the diagnostic workup of the misplaced (IUCD); but it is not reliable if the omentum and bowel loops surround the device. The X-ray can help confirm (US) result and exclude expulsion. Rarely (CT) is used for (IUCD) localization. However, the (CT) is the best for the evaluation of complications associated with intra-abdominal (IUCDs) 
and also has a role in determining the proper method of removal.

\section{References}

1. Boortz HE, Margolis DJA, Ragavendra N, Patel MK and Kadell BM. Migration of Intrauterine Devices: Radiologic Findings and Implications for Patient Care. RadioGraphics 2012; 32:335352.

2. Wildemeersch D, Hasskamp T and Norman D Goldstuck. Malposition and displacement of intrauterine devices diagnosis, management and prevention. Clin Obstet Gynecol Reprod Med. 2016; Volume 2(3): 183-188.

3. Michelle L, Stalnaker and Andrew M. Kaunitz. How to identify and localize IUDs on ultrasound. OBG Management 2014; Vol. 26 No. 8.

4. Rowlands S, Oloto E and David H Horwell. Intrauterine devices and risk of uterine perforation: current perspectives. Open Access Journal of Contraception 2016; 7 19-32.

5. Peri N, Graham D and Levine D. Imaging of Intrauterine Contraceptive Devices. J Ultrasound Med. 2007; 26:1389-1401.

6. El Saadi A, Mohandes I , Emad M and Abdulbaqim $\mathrm{H}$.The role of $\mathrm{CT}$ scan in laparoscopic retrieval of a perforated intrauterine device (IUD). Gynecol Surg 2004; 1:248-250.

7. Devassy R, Golpalakrishnan S, Torres-de la Roche LA, Verhoeven H, De Wilde MS and De Wilde RL. The missing intrauterine device. Int $\mathbf{J}$ Reprod Contracept Obstet Gynaecol 2016; 5:3587-9.

8. Ikechebelu JI and Mbamara SU. Laparoscopic retrieval of perforated intrauterine device. Niger J Clin Pract b. 2008; 11:394-5.

9. Adewale FB and Ashimi A. Missing intrauterine contraceptive device string. Diagnosis and management at Federal Medical Centre, Bida
Northcentral Nigeria. Trop J Obstet Gynaecol 2018; 35:298-303. 91.

10.Kaplanoğlu1 M, Bülbül M, Yüce T, Kaplanoğlu $D$ and Aban M Mislocated extrauterine intrauterine devices: Diagnosis and surgical management. J Turk Ger Gynecol Assoc 2015; 16: 91-5.

11. Varun N, Jain A, Nigam A, Noor S, Gupta N and Sharma S. Approach Towards Misplaced or Malposition IUCD: Lessons Learned. Journal of Clinical and Diagnostic Research 2019; 40534.12835.

12. Gupta $M$ and Jain G. Misplaced IUCD: Challenges and Management. PJSR. 2016; 9(2):14-17.

13.Elahi $\mathrm{N}$ and Koukab $\mathrm{H}$. Diagnosis and Management of Lost Intrauterine Contraceptive Device. JPMA 2002; 52:18.

14. Adebayo AA, Olumide AT, Akujuobi OR, Oluseyi AI, Adewumi B and Olabisi AT, et al. Misplaced ("Missing") Intrauterine Contraceptive Device Among Clients at a Rural Tertiary Hospital in South Western Nigeria. Journal of Gynecology and Obstetrics 2019; 7(2): 51-55.

15.Ezegwui HU, Ikeako LC and Egbuji C. Missing Intrauterine Contraceptive Device among Clients in Enugu. Niger J Surg 2011; 17(2):60-63. 90.

16. Montaser $\mathrm{H}$, Elhelwand $\mathrm{E}$ and Hamed A. Role of VCI -OMNIVEIW (4D Ultrasound technology) in accurate and fast detection of IUCD complications. Ejpmr 2017; 4(06), 17-25.

17.Ibitoye BO, Aremu AA, Onuwaje MA and Ayoola OO. What is the fate of the missing intrauterine contraceptive device? TROPICAL DOCTOR 2009; 39: 221-223.

18. Barsaul M, Sharma N and Sangwan K. 324 Cases of misplaced IUCD - a 5-year study.TROPICAL DOCTOR 2003; 33, 11-12.

To cite this article: Hesham E. Elsheikh, Manal A. ElRefaei, Sara F. Abd Elfattah. Assessment of Misplaced Intrauterine Contraceptive Devices by Different Imaging Modalities: A Crosssectional Study. BMFJ 2021;38(Radiology): 137-146. DOI: 10.21608/bmfj.2021.53109.1357 